\title{
Three Arguments against the Expertise Defense
}

\author{
Moti Mizrahi
}

Forthcoming in Metaphilosophy

\begin{abstract}
Experimental philosophers have challenged friends of the expertise defense to show that (a) the intuitive judgments of professional philosophers are different from the intuitive judgments of non-philosophers, and (b) the intuitive judgments of professional philosophers are better than the intuitive judgments of non-philosophers, in ways that are relevant to the truth or falsity of such judgments. Friends of the expertise defense have responded by arguing that the burden of proof lies with experimental philosophers. In this paper, I sketch three arguments which show that both (a) and (b) are probably false. If my arguments are cogent, then shifting the burden of proof is a futile move, since philosophical training makes no significant difference as far as making intuitive judgments in response to hypothetical cases in concerned.
\end{abstract}

Keywords: experimental philosophy; expertise defense; intuition; metaphilosophy; thought experiments

\section{Introduction}

Experimental studies suggest that intuitive judgments in response to hypothetical cases are subject to order effects (see, e.g., Lombrozo 2009), framing effects (see, e.g., Petrinovich and O’Neill 1996), and environmental factors (see, e.g., Helzer and Pizarro 2011). Further research shows that people's moral judgments can be affected by the food they taste. For example, Eskine et al (2011) show that people are more likely to make harsher moral judgments after they taste something disgusting. These factors are clearly not relevant to the truth or falsity of such judgments.

In response to these and other experimental studies which show that intuitive judgments are influenced by irrelevant factors (see also Machery et al 2004), critics of experimental philosophy have argued that only the intuitive judgments of experts (i.e., professional philosophers) should count as evidence in philosophical arguments (see, e.g., Williamson 2005; Hales 2006; Kauppinen 2007; Ludwig 2007; Sosa 2007). If friends of the "expertise defense" are right, then, unlike the intuitive judgments of non-philosophers ("novices"), the intuitive judgments of professional philosophers ("experts") are significantly less likely to be affected by factors that are irrelevant to the truth or falsity of such judgments. As Weinberg et al (2010) argue, for the expertise defense to succeed, critics of experimental philosophy have to show that

(a) The intuitive judgments of experts (professional philosophers) are different from the intuitive judgment of novices (non-philosophers) in a way that is relevant to the truth or falsity of such judgments; 
(b) The intuitive judgments of experts (professional philosophers) are better than the intuitive judgments of novices (non-philosophers) in a way that is relevant to the truth or falsity of such judgments.

In other words, if there is any truth to the expertise defense, then "the [...] intuitions of philosophers must be different from the [...] intuitions of non-philosopher experimental participants, and it must be less likely that the [...] intuitions of philosophers are significantly influenced by factors that are irrelevant to the truth of these intuitions" (Tobia et al 2013, 630).

More recently, some friends of the expertise defense have argued that the burden of proof lies with experimental philosophers. For instance, according to Williamson (2011), if experimental philosophers want to use data on non-philosophers to draw conclusions about professional philosophers, they have to show that professional training in philosophy makes no substantial difference insofar as making intuitive judgments in response to hypothetical cases is concerned. As Williamson $(2011,226)$ writes:

The experimental critique presents evidence that philosophically untrained subjects perform poorly at thought experimentation, a cognitive task characteristic of contemporary analytic philosophy. In general, given a cognitive task characteristic of a discipline, it is unwarranted to project data about the performance at the task of subjects untrained in the discipline onto subjects trained in the discipline, without specific evidence that training in the discipline makes no substantial difference to skill at that task. [Weinberg et al's (2010)] attempt to provide such specific evidence consists of a few vague and casual claims about training in philosophy and thought experimentation. They provide no significant evidence that thought experimentation is worse off in the relevant respects than the cognitive skills they acknowledge to be enhanced by training in philosophy, such as informal argumentation and the close analysis of texts. Consequently, they provide no reason to rely less on trained philosophers' skill at thought experimentation than on their skill at those other cognitive tasks.

In what follows, I aim to turn what Williamson says are "vague and casual claims" into explicit arguments. I sketch three arguments which show that both (a) and (b) are probably false. If my arguments are cogent, then shifting the burden of proof back to experimental philosophers will not do, since a major claim that is a crucial part of this move would then be false, namely, that philosophical training makes one better at making intuitive judgments in response to hypothetical cases. ${ }^{1}$

\section{Two arguments from experimental results}

As Alexander and Weinberg (2007) point out, friends of the expertise defense make an empirical claim, namely, that as a matter of fact professional philosophers ("experts") are not as affected by extraneous influences, such as the order in which hypothetical cases are presented, as non-

\footnotetext{
${ }^{1}$ For additional arguments against the method of cases and appeals to intuitions elicited from hypothetical cases, see Mizrahi (2012), (2013), and (2014).
} 
philosophers ("novices"). ${ }^{2}$ However, more recent experimental studies show that the intuitive judgments of professional philosophers are affected by the same irrelevant factors as the intuitive judgments of non-philosophers. For example:

\section{Persistent bias in expert judgments about free will and moral responsibility}

Schulz et al (2011) provide evidence that directly challenges that expertise defense. ${ }^{3}$ Their experiment shows that professional philosophers display similar kinds of effects as non-philosophers. In particular, their study shows that, like the intuitive judgments of novices, the intuitive judgments of professional philosophers whose area of research is free will are influenced by an irrelevant factor, namely, the personality trait extraversion. In their study, Schulz et al (2011) compare the intuitive judgments of professional philosophers who are well-versed in the free will and moral responsibility debate (which they determined using a performance test they call the Free Will Test) with those of nonphilosophers. Their results show that extraversion was systematically linked to compatibilist judgments without a noticeable difference between the judgments of experts and those of novices, and that warmth (an aspect of extraversion) was a predictor of a moderate amount of unique judgment variance even when controlling for expertise. Accordingly, these results show that an irrelevant factor, namely, personality, continues to have a significant effect on intuitive judgments even when the judgments are made by experts. As Schulz et al $(2011,1729)$ put it, "after controlling for verifiable expert knowledge of philosophical debates concerning free will and moral responsibility, extraversion continues to predict compatibilist judgment biases."

\section{Order effects on moral judgment in experts and novices}

A study conducted by Schwitzgebel and Cushman (2012) shows that the intuitive judgments of professional philosophers (MA or PhD in philosophy), academics who are not philosophers (MA or PhD in an area other than philosophy), and non-academics (no MA or PhD) are subject to similar order effects (in terms of the order in which hypothetical cases are presented) despite the fact that these hypothetical cases are about moral principles that professional philosophers should be familiar with (e.g., the doctrine of double effect and the principle of moral luck). As Schwitzgebel and Cushman (2012, 150) write, "even professional philosophers' judgments about familiar types of cases in their own field can be strongly and covertly influenced by psychological factors that they would not endorse upon reflection, and [...] such unwanted influences can in turn strongly influence the general principles those philosophers endorse." That is, Schwitzgebel and Cushman (2012) detected order effects not only on philosophers' judgments about hypothetical cases but also on their endorsement of general principles. Accordingly, these results show that an irrelevant factor, namely, order of presentation, continues to have a significant effect on intuitive judgments even when the judgments are

\footnotetext{
${ }^{2}$ See also Weinberg (2007).

${ }^{3}$ There is also a growing body of evidence that indirectly challenges the expertise defense. For example, Schwitzgebel (2009) presents evidence suggesting that ethicists, on average, do not behave better than non-ethicists. Schwitzgebel and Rust (2009) show that philosophers generally do not believe that ethicists behave substantially better than other philosophers.
} 
made by experts. As Schwitzgebel and Cushman $(2012,147)$ put it, "Our analysis found no support for the view that philosophical expertise enhances the stability of moral judgment against order effects."

\section{Framing effects on moral judgment in experts and novices}

Two studies conducted by Tobia et al (2013a) show that the intuitive judgments of both professional philosophers (who were surveyed at the American Philosophical Association Pacific Division meeting in April 2011) and non-philosophers are influenced by whether hypothetical cases are framed in the second person or the third person. This particular type of framing effect is known as the Actor-Observer bias, since the experimental subject is depicted either as the actor or as the observer in a hypothetical scenario. In the first experiment, Tobia et al (2013a) found significant framing effects on the intuitive judgments of professional philosophers in response to the "Jim and the Natives" case from Smart and Williams $(1973,98)$. In the second experiment, the intuitive judgments of professional philosophers in response to the Trolley Switch case also displayed significant framing effects. Accordingly, these results show that an irrelevant factor, namely, a type of framing effect known as the Actor-Observer bias, continues to have a significant effect on intuitive judgments even when the judgments are made by experts. As Tobia et al (2013a, 634) put it, "both non-philosophers and philosophers are subject to a type of framing effect, the Actor-Observer bias, when making judgments of moral permissibility and moral obligation."

\section{Cleanliness effects on moral judgment in experts and novices}

A study conducted by Tobia et al (2013b) shows that the actual smell of a questionnaire (in particular, whether the questionnaire smelled of Lysol or not) influenced both professional philosophers and non-philosophers in the way they answered the questionnaire. Tobia et al (2013b) presented undergraduate students and professional philosophers (attendees of the 2011 American Philosophical Association Eastern Division meeting) with moral purity scenarios. The study was designed to manipulate two variables: actor vs. observer scenarios and clean (sprayed with Lysol) vs. control (sprayed with water) surveys. Tobia et al (2013b) have found that philosophers rated others more harshly than themselves, whereas students rated themselves more harshly than others, thus replicating their previous results (Tobia et al 2013a). In addition, they have found that cleanliness made students give higher ratings in the actor and the observer scenarios, but made philosophers give higher ratings in the actor scenarios and lower ratings in the observer scenarios. In other words, the cleanliness effect operated in opposite directions for students and philosophers. This is no consolation for friends of the expertise defense, as Tobia et al $(2013 \mathrm{~b}, 201)$ point out, because these results still show that "philosophers are subject to actor-observer effects and are influenced by cleanliness cues." Accordingly, these results show that irrelevant factors, namely, a type of framing effect known as the Actor-Observer bias and an unconscious cleanliness prime, continue to have a significant effect on intuitive judgments even when the judgments are made by experts. As Tobia et al $(2013 b, 202)$ put it, "the intuitive judgments of both nonphilosophers and philosophers are influenced by a seemingly irrelevant environmental factor: an unconscious cleanliness prime." 
These studies, then, directly challenge (a), since they show that the intuitive judgments of both philosophers and non-philosophers display similar biases. Based on these experimental results, then, the following argument can be made against (a):

\section{Argument I}

(P1) If (a), then, unlike the intuitive judgments of non-philosophers, which are affected by irrelevant factors, the intuitive judgments of philosophers are unaffected by irrelevant factors.

(P2) The intuitive judgments of philosophers, just like the intuitive judgments of nonphilosophers, are affected by irrelevant factors.

(C1) Therefore, it is not the case that (a).

That is, it is not the case that the intuitive judgments of professional philosophers are different from those of non-philosophers in a way that is relevant to the truth or falsity of such judgments.

Argument I is deductively valid and a growing body of experimental evidence supports (P2). ${ }^{4}$ If Argument I is sound, then it shows that (a) is false. This result is a significant blow to the expertise defense, of course, because it directly challenges the claim that professional philosophers ("experts") are significantly less susceptible to these sorts of biases than nonphilosophers ("novices") are.

A stronger argument, I submit, can be made against (a) as well as against (b). The following argument, if sound, shows that, far from being different or better, the intuitive judgments of both novices and experts are unreliable truth-trackers.

\section{Argument II}

(P3) Intuitive judgments (whether of philosophers or non-philosophers) are reliable truth-trackers only if they are unaffected by irrelevant factors.

(P4) Intuitive judgments (of professional philosophers or non-philosophers) are affected by irrelevant factors.

(C2) Therefore, intuitive judgments are unreliable truth-trackers.

(C2) is clearly a stronger claim than (C1). If (C2) is true, then it means that intuitive judgments in response to hypothetical cases are unreliable truth-trackers, i.e., they are unlikely to tell us anything true about the subject matter under investigation. (See also Mizrahi 2014.)

The crucial premise of Argument II is (P3). Could friends of the expertise defense reject (P3)? I don't think so. Here is why. (P3) is an instance of the following principle:

Judgment $J$ about subject matter $S$ reliably tracks truths about $S$ only if $J$ is unaffected by factors that are irrelevant to the truth or falsity of $J$.

\footnotetext{
${ }^{4}$ See also Sytsma and Machery (2010), Machery (2012), and Knobe and Samuels (2013).
} 
This principle, I submit, is generally true. To see why, suppose that I watch Christiano Ronaldo take a free-kick and score a goal. I immediately judge that this is the best free-kick I have ever seen. I have a strong immediate belief that this is the best free-kick I have ever seen. Now, suppose that I am a Manchester United fan, and after Ronaldo's move to Real Madrid, his freekicks don't seem all that great to me anymore. In this case, my judgments about the quality of Ronaldo's free-kicks are affected by an irrelevant factor, namely, my love for a particular soccer team. So we shouldn't put much confidence in my judgments about players' free-kicks, since I am likely to judge more favorably the free-kicks of players who play for my favorite team. In other words, biases, such as supporting a particular sports team, can cloud our judgments. That is why we rely on impartial judges to referee sports matches.

Consider another example. Suppose I look at a painting in a museum and the painting strikes me as beautiful. Now suppose a curator passes by and I ask her about the identity of the artist. She tells me that the artist's name is Congo and that he was a chimpanzee. After she tells me that, I look at the painting again, and it no longer strikes me as beautiful. In this case, my aesthetic judgment is affected by an irrelevant factor, namely, the species of the artist. Arguably, the fact that an artist is not a member of the species Homo sapiens is irrelevant to whether a painting is beautiful or not. Again, we shouldn't put much confidence in my aesthetic judgments, since I am likely to judge more favorably the paintings of those who are members of my species.

If this is correct, then Argument II is deductively valid and a growing body of experimental evidence supports ( $\mathrm{P} 4)$. At this point, friends of the expertise defense might insist that the intuitive judgments of professional philosophers are somehow better than the intuitive judgments of non-philosophers. Presumably, the idea here is that philosophical training is supposed to make one's intuitive judgments better (i.e., more reliable) than the intuitive judgments of non-philosophers. Williamson (2011, 225), for instance, thinks that "philosophical training with respect to thought experiments may have about two and a half of the three characteristics conducive to the production of genuine expertise." These characteristics are:

i. $\quad$ repetitive practice with fast, accurate feedback;

ii. decomposition of the task into sub-tasks;

iii. use of external decision aids.

Williamson $(2011,224)$ argues that Weinberg et al (2010) fail to provide "serious evidence of deficiency" with respect to these characteristics, and thus they fail to shift the burden of proof on to friends of the expertise defense.

In that respect, it is important to note that the aforementioned experimental studies, whose results directly challenge the expertise defense, are framed by their authors mostly as attempts to shift the burden of proof back to friends of the expertise defense. For instance, Schultz et al $(2011,1727)$ argue that "Those who wish to maintain the expertise defense must provide some actual evidence that expertise (however operationalized) makes a difference relevant to supporting the expertise defense." Likewise, Tobia et al $(2013,635)$ argue that "advocates of the expertise defense need to offer some evidence of their own."

In the next section, I sketch another argument against the expertise defense. This argument shows that intuitive judgments are probably not the sort of thing that can get better by 
training. If this argument is cogent, then shifting the burden of proof is a futile move, since making intuitive judgments in response to hypothetical cases is probably not the sort of thing that can be improved with practice.

\section{An analogical argument}

I think that friends of the expertise defense have a more serious problem than the arguments from experimental results outlined in Section 2. To see why, a few words about the epistemology of intuitions are in order. Several philosophers have argued that intellectual intuition and sense perception are analogous in epistemically relevant respects. For example, according to Sosa (1996, 154):

Seemings, then, whether sensory or intellectual, might be viewed as inclinations to believe on the basis of direct experience (sensory) or understanding (intellectual) and regardless of any collateral reasoning, memory, or introspection where the objects of intellectual seeming also present themselves as necessary (original emphasis).

Arguably, the most prominent, recent proponent of the perception-intuition analogy is Chudnoff (2011a, 2011b). In a recent paper, Chudnoff $(2013,362-364)$ argues in support of the following analogy between perceptual knowledge and intuitive knowledge:

Perceptual Knowledge (PK): If a perception makes a belief that $\mathrm{p}$ based on it amount to knowledge, it does so in virtue of (1) being an experience in which it perceptually appears to you that $\mathrm{p}$, and (2) being an experience in which you are sensorily aware of an item o, such that (3) o makes p true.

Intuitive Knowledge (IK): If an intuition makes a belief that $\mathrm{p}$ based on it amount to knowledge, it does so in virtue of (1) being an experience in which it intuitively appears to you that p, and (2) being an experience in which you are intellectually aware of an item o, such that (3) o makes $p$ true.

Chudnoff $(2013,364)$ goes on to say that (PK) and (IK) are obviously analogous:

The structural parallels between (IK) and (PK) should be obvious. The differences are that intuitive appearance replaces perceptual appearance and intellectual awareness replaces sensory awareness.

If Chudnoff is right, then in much the same way that $S$ is justified in believing that $p$, where $p$ is the content of a sensory appearance in virtue of which $S$ is sensorily aware of an object $O$ that makes $p$ true, $S$ is justified in believing that $p$, where $p$ is the content of an intellectual appearance in virtue of which $S$ is intellectually aware of an object $O$ that makes $p$ true. Unlike the concrete objects of perception, however, the objects of intuition are abstract, according to Chudnoff (2013).

Like Chudnoff, Hales (2012) also invokes the perception-intuition analogy in his defense of the epistemic role of rational intuition. According to Hales $(2012,180)$ : 
there is a faculty of rational intuition that delivers prima facie justified beliefs about philosophical propositions. [...] If anything is a faculty, then sense perception is. If intuition is sufficiently similar to perception, then it too counts as a faculty. Moreover, if perception produces prima facie justified beliefs about its target subject matter and thereby serves as a source of knowledge, then so does intuition.

If Hales is right, then we should treat rational intuition as a source of prima facie justification in much the same way that we treat perception as a source of prima facie justification.

If these philosophers are right about the perception-intuition analogy, which means that intellectual seemings and sensory seemings are both seemings, i.e., both are relations between a subject (a perceiver) and an object of either sensory (as when something strikes the subject as being red) or intellectual perception (as when something strikes the subject as being true), then it is reasonable to expect that perception and intuition would be similar in other respects as well. The relevant respect in terms of which sensory seemings and intellectual seemings are similar is their inability to be improved upon by training. Here is why:

\section{Argument III}

(P5) Perceptual judgments are sensory seemings that cannot be improved with training (e.g., the sky still seems blue even to a geophysicist who is an expert on the atmosphere; training doesn't change one's sense perceptions, let alone makes them better).

(P6) Like perceptual judgments, intuitive judgments are also seemings, albeit intellectual rather than sensory seemings (e.g., it seems wrong to push the fat man off the bridge).

(C3) Therefore, like perceptual judgments, intuitive judgments cannot be improved with training (i.e., training doesn't change one's intuitions, let alone makes them better).

If Argument III is cogent, then it shows that friends of the expertise defense cannot meet Weinberg et al's (2010) challenge. Recall that the challenge is to show that (a) the intuitive judgments of philosophers are different from the intuitive judgments of non-philosophers, and (b) the intuitive judgments of philosophers are better than the intuitive judgments of nonphilosophers, in ways that are relevant to the truth or falsity of such judgments. If Argument III is cogent, then friends of the expertise defense cannot show that (b) is true, since intuitions are probably not the sort of thing that can get better (or even change) with training and practice. In other words, if (C3) is true, then (b) cannot be true, since (C3) means that one cannot get better at making intuitive judgments in response to hypothetical cases with philosophical training.

It is worth emphasizing that Argument III is an argument by analogy. As such, its premises provide evidence for its conclusion but do not logically entail it. Since Argument III is an analogical argument, an obvious objection is to argue that the analogy is weak, i.e., that there are relevant dissimilarities between sensory seemings and intellectual seemings. (Recall that most defenders of the evidential role of intuition accept the perception-intuition analogy.) The analogy is as follows: 


\section{Sensory seemings : training $::$ intellectual seemings : training}

Just as sensory seemings cannot become better through training, intellectual seemings cannot become better through training. It looks like a very strong analogy. In fact, there is another relevant similarity between sensory seemings and intellectual seemings. That is, it is not clear what it even means for sensory seemings to be better. Can one become better at seeing colors, say, through training? Similarly, it is not clear what it even means for intellectual seemings to be better. In other words, since sensory seemings are relations between a subject and an object of perception, it is not clear what makes one relation better (i.e., more reliable) than another. Similarly, since intellectual seemings are relations between a subject and an object of cognition, it is not clear what makes one relation better (i.e., more reliable) than another.

There is another move that is open to friends of the expertise defense, although they would have to amend the expertise part of the expertise defense. That is to say, friends of the expertise defense could concede that intuitions are not the sort of thing that can be improved through training, just like sensory perceptions, but then argue that some people are innately better than others at making intuitive judgments in response to philosophical thought experiments, just as some people have better eyesight than others. ${ }^{5}$

The most obvious problem with this line of argument is how to tell who has innate philosophical intuition. Friends of the expertise defense could say something along these lines:

Those who have innate philosophical intuition are those who make intuitive judgments in response to philosophical thought experiments that align with what most (all?) professional philosophers intuitively judge.

But now it seems that friends of the expertise defense are trapped in a vicious circle. For they have said that the intuitive judgments of professional philosophers are better than those of nonphilosophers because philosophers have innate philosophical intuition, and then they said that we tell who has innate philosophical intuition by the way in which people respond to philosophical thought experiments. The problem, it seems, is that there is no independent, non-circular standard by which to judge which intuitive judgments are better.

It is important to note that the perception-intuition analogy, which is accepted by many defenders of the evidential role intuitions in philosophy, can be treated as an empirical hypothesis. That is, sense perception, which is taken to be better understood than intellectual intuition, is supposed to be a model for intellectual intuition. In that respect, the hypothesis that sense perception models intellectual intuition could - at least in principle - turn out to be false. But if sense perception does indeed accurately model intellectual intuition, then that intuition does not improve with practice is precisely what we would expect, given that sense perception does not improve with practice. For this reason, the aforementioned experimental results can be seen as evidence in support of the perception-intuition analogy. Recall that these experimental studies show that there is no significant difference between the intuitions of experts and novices,

\footnotetext{
${ }^{5}$ Note that no amount of training or exercise can improve one's eyesight, despite the claims of quacks to the contrary. See, for example, Pollack (1956) on the thoroughly discredited "Bates method for better eyesight."
} 
which is precisely what we would expect if intuitions, just like sense perceptions, are not the sort of thing that improves with practice. ${ }^{6}$

\section{Conclusion}

Experimental philosophers have challenged friends of the expertise defense to show that (a) the intuitive judgments of professional philosophers are different from the intuitive judgments of non-philosophers, and (b) the intuitive judgments of professional philosophers are better than the intuitive judgments of non-philosophers, in ways that are relevant to the truth or falsity of such judgments. In response, friends of the expertise defense have argued that the burden of proof lies with experimental philosophers.

In this paper, I have sketched three arguments which show that friends of the expertise defense cannot meet the challenge issued by experimental philosophers and that shifting the burden of proof is a futile move. First, Argument I shows that (a) is probably false. Second, Argument II shows that (a) and (b) are probably false. Third, Argument III shows that, if sensory perception is a model for intellectual intuition, then, much like sensory perceptions, intuitions are probably not the sort of thing that can be improved with training and practice. If these arguments are cogent, then trying to shift the burden of proof back to experimental philosophers is a futile move, since philosophical training makes no significant difference as far as making intuitive judgments in response to hypothetical cases in concerned.

\section{Acknowledgments}

An earlier version of this paper was presented at the fiftieth-anniversary conference of the Long Island Philosophical Society in Molloy College. A later version was accepted for presentation at the 2014 Buffalo Annual Experimental Philosophy Conference. I would like to thank the organizers of both conferences. I am also grateful to an anonymous reviewer of Metaphilosophy for helpful comments on earlier drafts of this paper.

\section{References}

Alexander, J. and Weinberg, J. (2007). Analytic Epistemology and Experimental Philosophy. Philosophy Compass, 2, 56-80.

Chudnoff, E. (2011a). The Nature of Intuitive Justification. Philosophical Studies, 153, 313-333.

Chudnoff, E. (2011b). What Intuitions Are Like? Philosophy and Phenomenological Research, $82,625-654$.

Chudnoff, E. (2013). Intuitive Knowledge. Philosophical Studies, 162, 359-378.

\footnotetext{
${ }^{6}$ Thanks to an anonymous reviewer of Metaphilosophy for this last point.
} 
Eskine, K. J., Kacinik, N. A., and Prinz, J. J. (2011). A Bad Taste in the Mouth: Gustatory Disgust Influences Moral Judgments. Psychological Science, 22, 295-299.

Hales, S. D. (2006). Relativism and Foundations of Philosophy. Cambridge, MA: The MIT Press.

Hales, S. D. (2012). The Faculty of Intuition. Analytic Philosophy, 53, 180-207.

Helzer, E. and Pizarro, D. (2011). Dirty Liberals: Reminders of Cleanliness Promote

Conservative Political and Moral Attitudes. Psychological Science, 22, 517-522.

Kauppinen, A. (2007). The Rise and Fall of Experimental Philosophy. Philosophical Explorations, 10, 95-118.

Knobe, J. and Samuels, R. (2013). Thinking Like a Scientist: Innateness as a Case Study.

Cognition, 126, 72-86.

Lombrozo, T. (2009). The Role of Moral Commitments in Moral Judgment. Cognitive Science, 33, 273-286.

Ludwig, K. (2007). The Epistemology of Thought Experiments: First Person versus Third Person Approaches. Midwest Studies in Philosophy, 31, 128-159.

Machery, E., Mallon, R., Nichols, S., and Stich, S. (2004). Semantics, Cross-cultural Style.

Cognition, 117, 361-366.

Machery, E. (2012). Expertise and Intuitions about Reference. Theoria, 27, 37-54.

Machery, E., Mallon, R., Nichols, S., and Stich, S. (2012). If Folk Intuitions Vary, Then What?

Philosophy and Phenomenological Research, 86, 618-635.

Mizrahi, M. (2012). “Intuition Mongering.” The Reasoner, 6, 169-170.

Mizrahi, M. (2013). “More Intuition Mongering.” The Reasoner, 7, 5-6.

Mizrahi, M. (2014). "Does the Method of Cases Rest on a Mistake? Review of Philosophy and Psychology, 5, 183-197.

Petrinovich, L. and O'Neill, P. (1996). Influence of Wording and Framing Effects on Moral Intuitions. Ethology and Sociobiology, 17, 145-171.

Pollack, P. (1956). The Truth about Eye Exercises. Philadelphia: Chilton.

Schulz, E., Cokely, E. T., and Feltz, A. (2011). Persistent Bias in Expert Judgments about Free Will and Moral Responsibility: A Test of the Expertise Defense. Consciousness and Cognition, 20, 1722-1731.

Schwitzgebel, E. (2009). Do Ethicists Steal More Books? Philosophical Psychology, 22, 711-725.

Schwitzgebel, E. and Rust, J. (2009). The Moral Behavior of Ethicists: Peer Opinion. Mind, 118, 1043-1059. 
Schwitzgebel, E. and Cushman, F. (2012). Expertise in Moral Reasoning? Order Effects on Moral Judgment in Professional Philosophers and Non-philosophers. Mind and Language, 27, 135-153.

Smart, J. J. C. and Williams, B. (1973). Utilitarianism: For and Against. New York: Cambridge University Press.

Sosa, E. (1996). Rational Intuition: Bealer on Its Nature and Epistemic Status. Philosophical Studies, 81, 151-162.

Sosa, E. (2007). Experimental Philosophy and Philosophical Intuition. Philosophical Studies, 132, 99-107.

Sytsma, J. and Machery, E. (2010). Two Conceptions of Subjective Experience. Philosophical Studies, 151, 299-327.

Tobia, K., Buckwalter, W., and Stich, S. (2013a). Moral Intuitions: Are Philosophers Experts? Philosophical Psychology, 26, 629-638.

Tobia, K., Chapman, G. B., and Stich, S. (2013b). Cleanliness is Next to Morality, Even for Philosophers. Journal of Consciousness Studies, 20, 195-204.

Weinberg, J. (2007). How to Challenge Intuitions Empirically without Risking Skepticism. Midwest Studies in Philosophy, 31, 318-343.

Weinberg, J. Gonnerman, C., Buckner, C. and Alexander, J. (2010). Are Philosophers Expert Intuiters? Philosophical Psychology, 23, 331-355.

Williamson, T. (2005). Armchair Philosophy, Metaphysical Modality and Counterfactual Thinking. Proceedings of the Aristotelian Society, 105, 1-23.

Williamson, T. (2011). Philosophical Expertise and the Burden of Proof. Metaphilosophy, 42, 215-229. 